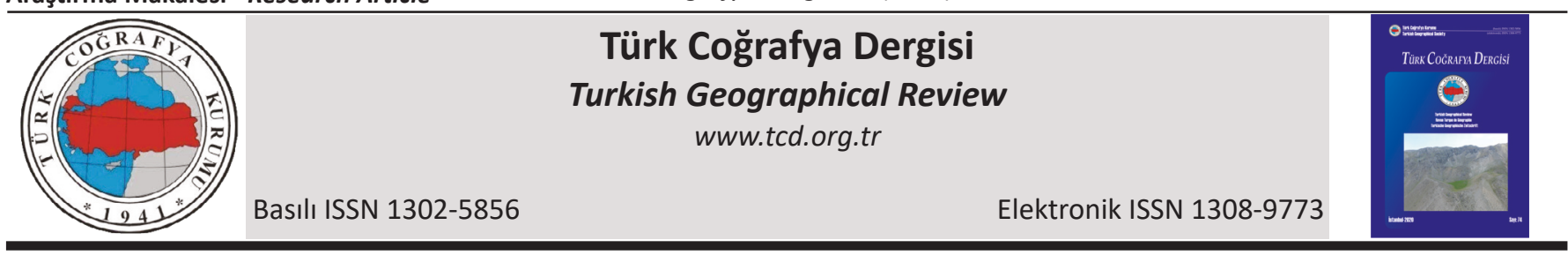

\title{
İspir Meşesinin farklı bir yayılış alanı: Hınzır Dağı (Akkışla-Kayseri)
}

\section{A different distribution area of Ispir Oak: Hınzır Mountain (Akkışla-Kayseri)}

\author{
Selahattin Polat ${ }^{\mathrm{a}}$ (D) İsmail Ege*a \\ ${ }^{a}$ Uşak Üniversitesi, Fen-Edebiyat Fakültesi, Coğrafya Bölümü, Uşak.
}

ORCID: S.P. 0000-0002-8042-1918; I.E. 0000-0001-5896-0440

\begin{tabular}{l} 
B I L G I / I N F O \\
\hline Geliş/Received: 30.11 .2019 \\
Kabul/Accepted: 29.05 .2020 \\
\hline Anahtar Kelimeler: \\
İspir meşesi \\
Endemik \\
Bitki örtüsü \\
Hınzır Dağı \\
Kayseri \\
Keywords: \\
Quercus syspirensis \\
Endemic \\
Flora \\
Hınzır Mountain \\
Kayseri province \\
LSorumluvar/Cor
\end{tabular}

*Sorumlu yazar/Corresponding author:

(i. Ege) ismail.ege@usak.edu.tr

DOI: $10.17211 /$ tcd. 653381

\section{Atif/Citation:}

Polat, S. ve Ege, í.(2020). İspir Meşesinin farklı bir yayılış alanı: Hınzır Dağı (AkkışlaKayseri). Türk Coğrafya Dergisi (74), 39-46. DOI: $10.17211 /$ tcd.653381

\begin{abstract}
ÖZ / ABSTRACT
Türkiye gerek tür zenginliği gerekse yaklaşık 6 milyon hektar meşe orman varlığıyla dünyanın sayılı ülkelerinden biridir. Türkiye'de doğal olarak yetişen 18 meşe türü ve bu türlerden 6 tanesinin 11 alt türü bulunmaktadır. Bunlardan Quercus vulcanica, Quercus macranthera subsp.syspirensis, Q.trojana subsp.yaltirikii endemik meşe türleridir. Meşe türleri içinde endemik bir alt tür olan İspir meşesi (Quercus macranthera subsp.syspirensis), Türkiye'nin Avrupa-Sibirya fitocoğrafya bölümleri içerisinde yer almaktadır. Bu tür Anadolu’nun kuzeyinde Karadeniz Bölgesi, iç̧ Anadolu Bölgesi'nin kuzeyi ve Doğu Anadolu Bölgesi'nin kuzey yarısında 1000-2250 m yükseltileri arasında yayılış gösterir. Mevcut bitki coğrafyası literatüründe İspir meşesinin Türkiye'deki doğal yayılış alanları içerisinde Erciyes Dağı üzerinde bulunduğu belirtilmektedir. İspir meşesinin Kayseri ilinin diğer yerlerinde varlığı bilinmemektedir. 2018 yılında Kayseri ilinin Akkışla İıçesi Ortaköy idari sınırları içinde Hınzır Dağı kuzeybatı yamacında yapılan arazi çalışmaları esnasında İspir meşesinin topluluk oluşturduğu görülmüştür. Burada 1600-1800 m yükselti basamakları arasında yayılış gösterir. İspir meşesi topluluğu çalı ve ağaç̧ık formuna sahip olup, toprak tabakasının zayıflığı ve çeşitli beşerî etkenlerden dolayı hayatta kalma mücadelesi vermektedir. Bu çalışma, daha önce hakkında detaylı araştırma yapılmamış İspir meşesinin Hınzır Dağı'ndaki doğal yayılışını konu almaktadır. Böylece bu türün Türkiye'de doğal yayılışı ile ilgili bilgilere katkı sağlanması amaçlanmaktadır.
\end{abstract}

Turkey is one of the few countries in the world with both species richness and about 6 million hectares of oak forest assets. There are 18 oak species growing naturally in Turkey and this kind of six of them are 11 subspecies. These are the endemic oak species Quercus vulcanica, Quercus macranthera subsp. syspirensis and Q.trojana subsp.yaltirikii. Ispir oak (Quercus macranthera subsp. syspirensis) which is an endemic sub-species of oak species is included in Turkey's Euro-Siberian department of biogeography. This species extends between 1000-2250 m elevations in the Black Sea Region in the north of Anatolia, the northern part of the Central Anatolia Region and the northern half of the Eastern Anatolia Region. It found that the existing plant geography ispir oak is stated in the literature on Mountain Erciyes in the natural occurrence in Turkey. Ispir oak is not known in other places of Kayseri province. In 2018, during the field surveys carried out on the northwestern slope of Hınzır Mountain within the administrative boundaries of the Akkışla district of Kayseri province, it was observed that ispir oak formed a community. In here, it is distributed between 1600$1800 \mathrm{~m}$ elevation steps. Ispir oak community has a bush and shrub form and struggles to survive due to weakness of soil layer and various human factors. This study focuses on the natural spread of ispir oak, which has not been studied in detail before, on the Hınzır Mountain. Thus, information about the natural distribution of such additives is intended to ensure in Turkey.

\section{Giriş}

Dünyada meşeler yaklaşık 400-500 türle temsil edilmektedir. Türkiye gerek tür zenginliği gerekse yaklaşık 6 milyon hektar meşe orman varlığıyla dünyanın sayılı meşe diyarlarından birisidir. Orman Genel Müdürlüğü (OGM, 2015) verilerine göre ülkemizde toplam orman alanı yaklaşık 22,3 milyon ha olup, bunun 12,7 milyon ha'lık (\% 57) kısmı normal kapalı, 9,6 milyon ha (\% 43)'lık kısmı ise boşluklu kapalılığa sahip orman statüsündedir. Türkiye'de doğal olarak yetişen 18 meşe türü ve bu türlerden 6 tanesinin 11 alt türü bulunmaktadır. Quercus vulcanica, Quercus macranthera subsp.syspirensis, Q.trojana subsp.yaltirikii ülkemiz için endemiktir (Akkemik, 2014; 2016). 
Araştırma sahası, İç Anadolu Bölgesi'nin Yukarı Kızılırmak Bölümü içerisinde yer alır. Daha ayrıntılı lokasyon belirtilecek olursak; Kayseri ili, Akkışla ilçesi, Ortaköy yerleşmesinin güneydoğusunda, Hınzır Dağı'nın (2477 m) kuzeybat eteklerindedir. İspir meşesi (Quercus macranthera subsp.syspirensis) bu dağın 1600-1800 metre yükseltileri arasında yayılış gösterir. Yaklaşık $6376 \mathrm{~m}^{2}$ lik alana sahiptir (Şekil 1).

Meşeler; odunlarının anatomik yapıları, meyvelerinin olgunlaşma süresi, yaprak ve kabuk özelliklerine göre 3 gruba ayrılmaktadır (Anşin ve Özkan, 2006; Çağlar, 2003). Akmeşeler grubunu Doğu Karadeniz meşesi (Quercus pontica), Istranca meşesi (Quercus hartwissiana), kasnak meşesi (Quercus vulcanica), Macar meşesi (Quercus frainetto), mazı meşesi (Quercus infectoria), saplı meşe (Quercus robur), sapsız meşe (Quercus petraea), tüylü meşe (Quercus pubescens) ve İspir meşesi (Quercus macranthera subsp.syspirensis) gibi türler, kırmızı meşeler grubunu İran palamut meşesi (Quercus brantii), Lübnan meşesi (Quercus libani), Makedonya meşesi (Quercus trojana), saçlı meşe (Quercus cerris), Anadolu palamut meşesi (Quercus ithaburensis) meydana getirir. Herdem yeşil meşeler grubunda ise pırnal meşesi (Quercus ilex), kermez meşesi (Quercus coccifera) ve boz pırnal meşesi (Quercus aucheri) bulunur. Kırmızı meşeler, ak meşelerden yaprak loblarının uçlarında kılçıksı-dikensi çıkıntıya sahip olmaları ile kolaylıkla ayrılırlar.

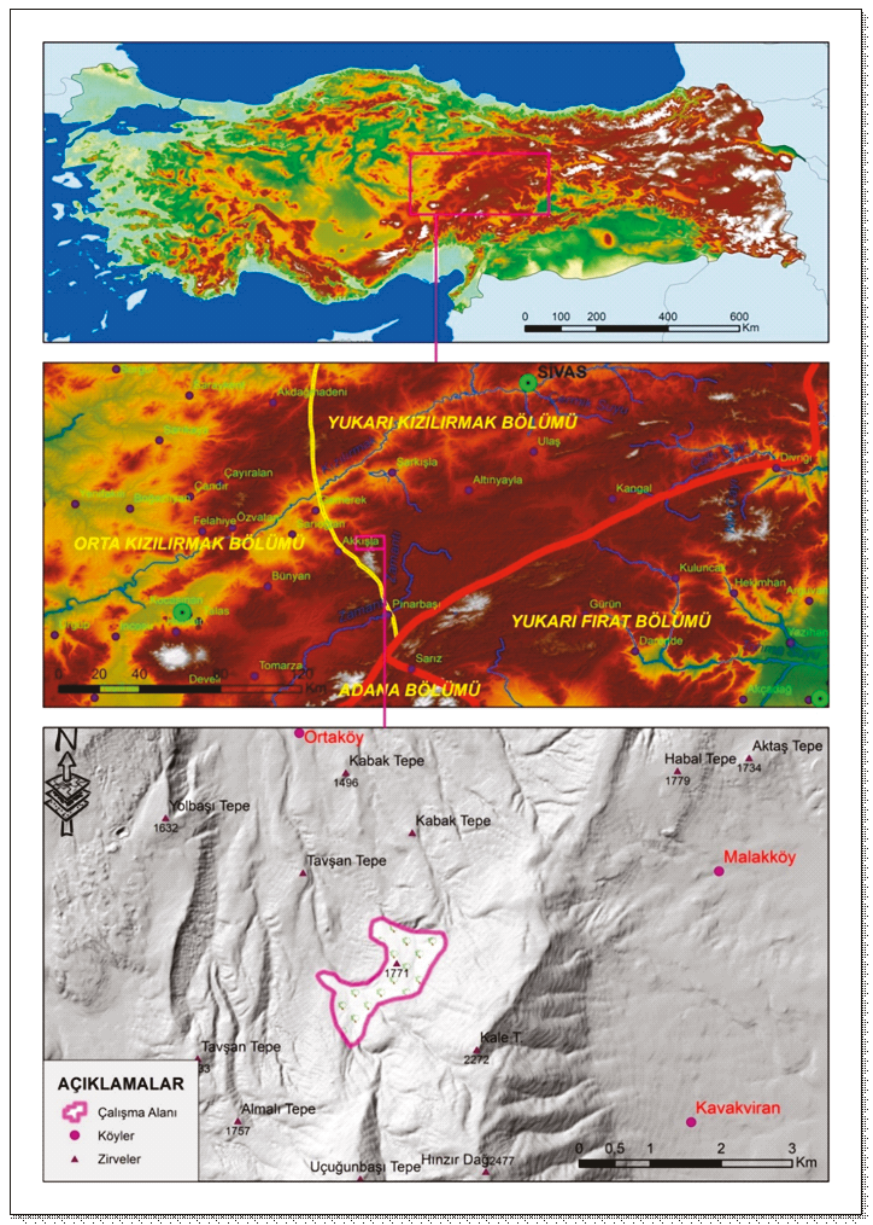

Şekil 1. Çalışma alanı lokasyon haritası

Figure 1. Location map of study area

Araştırmaya konu olan İspir meşesi, akmeşeler grubuna dâhildir. Quercus macranthera'nin (literatürde Kafkas meşesi olarak geçmekte) bir alt türü olan İspir meşesi (Quercus macranthera subsp.syspirensis) Türkiye'nin endemik meşe türlerinden biridir. Bu endemik alt tür, 6-7 metreye kadar boylanır ve yuvarlak bir tepe yapar. Ters yumurta şeklindeki yaprakları, sürgünlerin uç kısımlarında toplanmıştır (Foto 1). Yaprakların uzunluğu 5-10 cm, genişliği 3-5 cm arasında değişir. Üst yüzü koyu yeşil, alt yüzü sarımtrak kahverengindedir. Yaprak kalın olup, 5-9 tane tali lopukları olmayan düzenli loplara sahiptir. İspir meşesinin meyveleri sapsız veya 5-20 mm uzunluğunda çok kısa ve genellikle tüylüdür. Soğuğa karşı dayanıklıdır. Meyve kadehi, yarım küre biçiminde 1,5 cm çapındadır. Yarıküre şeklindeki kadehlerin pulları seyrek, sivri uçlu ve incedir (Yaltırık, 1984). Kadeh, palamudun $1 / 2$ veya $2 / 3$ kadarını içerisine almış bir şekilde olup 2-2,5 cm boyundadır. İspir meşesi düşük alkali ve kireçsiz kahverengi toprakları daha çok tercih eder.

Ülkemizde genel olarak 1000-1900 metre yükseltileri arasında yayılış gösteren İspir meşesinin (Q. syspirensis) sıcaklık isteği $a z$, nem isteği orta, kuraklığa ve düşük sıcaklığa dayanıklıdır (Browicz ve Zielinski, 1984). Kastamonu ve Çorum çevresinde dağ Iık kesimlerde 1200-1400 m, Akdağ, Zara ve Sivas çevresinde 1400-1500 metrenin üzerindeki seviyelerde yetişmektedir (Günal, 1997). Bununla birlikte Meyram Dağı'nın kuzey yamacında 2250 metreye kadar çıktığı tespit edilmiştir (Avcı, 1997).

Bu çalışma, İspir meşesinin daha önce hakkında detaylı araştırma yapılmamış olan Hınzır Dağı'ndaki doğal yayılışını konu almakta olup, bu türün Türkiye'de doğal yayılışı ile ilgili bilgilere katkıda bulunmayı amaçlamaktadır. Bitkinin yayılış gösterdiği Hınzır Dağı, bitki coğrafyası açısından önemli Anadolu Diyagonali (çaprazı) olarak nitelendirilen endemik ve relikt bitkiler bakımından zengin kuşağa yakın bir konumdadır.

\subsection{Malzeme ve Yöntem}

İspir meşesi (Quercus syspirensis)'nin Kayseri'nin Pınarbaşı, Akkışla, Bünyan ilçeleri arasında yükselen Hınzır Dağı'nın kuzeybatısında, idari açıdan Akkışla İlçesi'ne ait Ortaköy yerleşmesi güneyinde yayılış gösterdiği 2018 yılında yapılan arazi çalışmasında tespit edilmiştir.
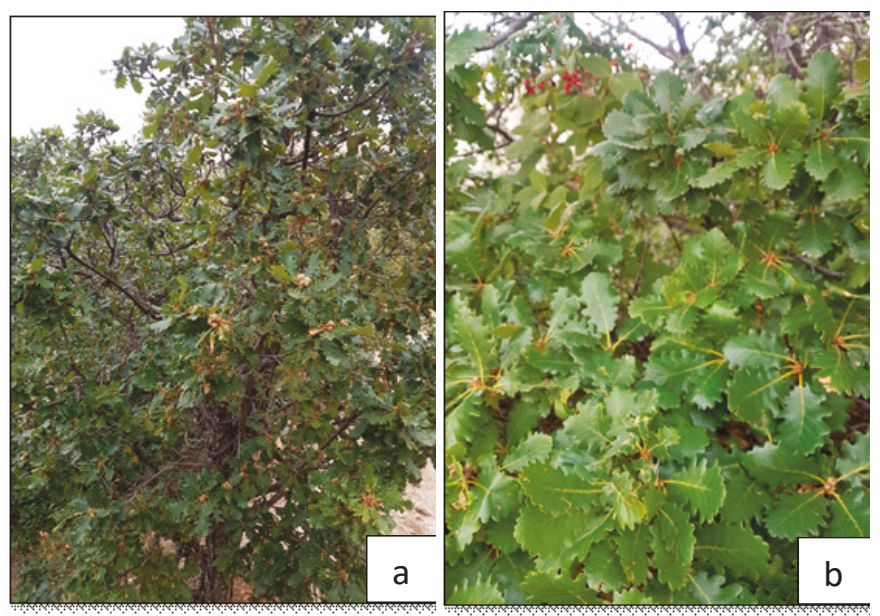

Fotoğraf 1. İspir meşesinin (a) (Quercus macranthera subsp.syspirensis) ve yapraklarının (b) yakından görünüşü.

Photo 1. Close-up view of the Ispir oak (a) (Quercus macranthera subsp.syspirensis) and leaves (b) 
İspir meşesinin, Kayseri ilinde Erciyes Dağı ve Ali Dağı'ndaki yayılış gösterdiği bilinirken (Ünaldı, 1996), bu sahadaki varlığı ile ilgili herhangi bir çalışmaya rastlanılmamıştır. Meşenin, Türkiye'deki yayılışı ile ilgili detaylı literatür taraması yapılmış, bitkinin yayılış gösterdiği alanda arazi çalışması gerçekleştirilerek, bu türe eşlik eden diğer türlere ait bitki örnekleri alınarak teşhisleri yapılmıştır. El tipi GPS ile yükselti değerleri alınmış ArcGIS 10.2 ile sahanın topografya ve jeoloji haritaları sayısallaştııımış, eğim ve bakı haritaları oluşturulmuştur. Ayrıca, alanın klimatolojik özellikleri ve toprak yapısına dair haritalar ve diğer görseller de oluşturulmuştur. Saha çalışmaları esnasında sahanın doğal ortam özellikleri ve özellikle de İspir meşesinin ekolojik özelliklerine yönelik gözlemlerde bulunulmuştur. İklim özelliklerinin ortaya konulmasında Şarkışla, Gemerek ve Pınarbaşı meteoroloji istasyonlarının uzun süreli rasat verilerinden yararlanılmıştır.

\section{2. İspir Meşesi'nin Türkiye'deki Yayılış Alanları}

Esas yayılış alanı Kafkaslar (Gürcistan, Azerbaycan, Ermenistan ve Rusya'nın güneyi) olan Quercus macranthera, buradan hem kuzey İran'a hem de kuzey Anadolu'ya sokulmuştur. Quercus macranthera'nın (Kafkas meşesi) ülkemizde yayılış gösteren alt türü Quercus macranthera subsp. syspirensis (İspir meşesi), esas yayılış alanı Kafkaslar olan Quercus macranthera subsp.macranthera'dan farklıdır (Browicz ve Zielinski, 1984).

Quercus macranthera'nın endemik bir alt türü olan İspir meşesi (Quercus macranthera subsp. syspirensis) ise Türkiye'nin Avrupa-Sibirya fitocoğrafya bölgelerinde özellikle Anadolu'nun kuzeyinde yayılış gösterir. Karadeniz Bölgesi, İç Anadolu Bölgesi'nin kuzeyi ve Doğu Anadolu Bölgesi'nin kuzey yarısı yayılış gösterdiği alanlardır (Şekil 2). Anadolu'da 1000-2250 metre yükseltileri arasında yayılış gösterir. Bursa, Bolu (Mudurnu), Zonguldak, Bartın, Karabük, Kastamonu (Küre Dağları), Sinop, Rize, Ankara (Beynam Dağı), Yozgat (Akdağmadeni), Çorum (İskilip), Amasya (Akdağ, Sana Dağı), Sivas (Yıldız Dağı, Zara çevresinde Avşardağı, Gemerek'te Karababa Dağı), Kayseri (Erciyes Dağı), Gümüşhane (Köse Dağı), Erzincan, Bayburt, Erzurum (Aşkale-Meyram Dağı, İspir), Kars (Göle), Bitlis, Elâzığ yayılış gösterdiği sahalardır (Hedge ve Yaltırık, 1982; Avcı, 1997; Öztürk, 2013). Doğu Anadolu Bölgesi'nde Tunceli (Pülümür) ve Bingöl civarında saf ormanlar oluşturur (Günal, 1997; Özüdoğru vd., 2010).

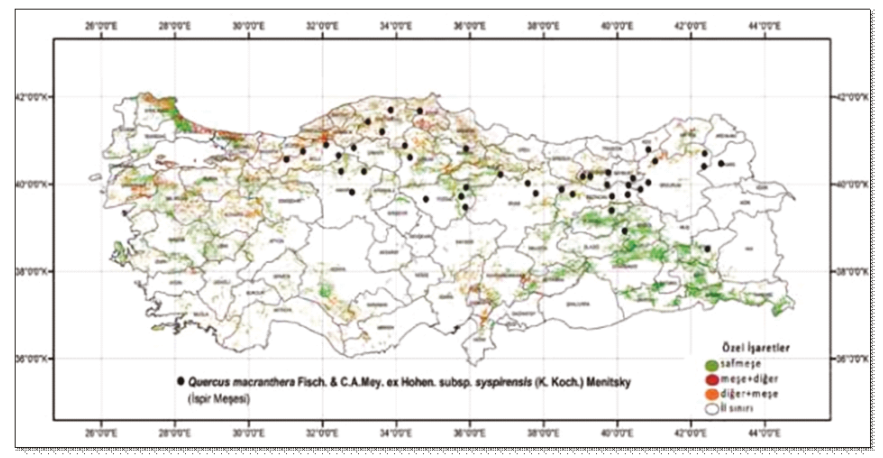

Şekil 2.Quercus macranthera subsp. syspirensis'in Türkiye'de yayılışı (Öztürk, 2013'den).

Figure 2.Distribution of Quercus acranthera subsp.syspirensis in Turkey (from Öztürk, 2013).
Ülkemizde yayılış gösteren meşe türleri içinde endemik bir alt tür olan İspir meşesi, 1000-2250 metre arasındaki yükseltilerde bazen saf, bazen de tüylü meşe (Quercus pubescens), karaçam (Pinus nigra), sarıçam (P. sylvestris), titrek kavak (Populus trémula), bodur ardıç (Juniperus communis subsp.nana) ile karışık topluluklar oluşturur (Kayacık, 1981; Yılmaz, 1998). Zohary'nin Alt Öksin sektöre ait türler içinde saydığı İspir meşesi (Zohary, 1973), inceleme alanındaki kütlelerin kuzey ve güney yamaçlarında yer alan orman kalıntılarından en sık rastlanan bir meşe türüdür.

Marmara Bölgesi'nde Uludağ'ın güneyinde kurakçıl orman içinde 1700 metre civarında karaçam ve göknar ormanları içinde sapsız meşe (O.petreae), İran akçaağacı (A.hyrcanum) ile birlikte yer almaktadır (Atalay, 1994).

Orta Karadeniz Bölümü'nde Amasya-Lâdik arasındaki alanda, Yeşilırmak vadisinin batısında yer alan yükseltisi 1400 metreyi geçen tepeler İspir meşesinin ormanlar oluşturduğu alanlardır (Günal, 1997). Özellikle burada Akdağ’ın kuzeyi en önemli yayılış gösterdiği sahalardan biri olup, 1800 metreye kadar çıkar.

Akdağmadeni, Zara ve Sivas çevrelerindeki dağlık alanlarda 1400-1500 metrenin üzerindeki seviyeleri yetişme ortamı olarak seçen İspir meşesi, karaçam ve sarıçam ormanlarına karışarak ya da saf ormanlar oluşturarak 1800-1900 metreye kadar yükselir (Günal, 1997).

Doğu Karadeniz'de Artvin-Hatila vadisinde 800-1400 metrelerde İspir meşesi, doğu kayını (F.orientalis), dağ karaağacı (Ulmus glabra), Kafkas Ihlamuru (Tilia rubra), adi gürgen (Carpinus betulus) ve Doğu Karadeniz akçaağacı (Acer cappadocium) ile birlikte bulunur. Özellikle Çoruh vadisinde İspir (Erzurum) çevresinde görülür. Burada 1000-1900 metre yükseltileri arasında yer alır (Atalay, 1994; 2017). Yarı kurak ortamlarda ise karaçam, sarıçam diğer meşelerden tüylü meşe, titrek kavakla birlikte topluluk oluşturan küçük ağaçttr.

Erzincan ve Gümüşhane çevresi, Quercus syspirensis'nin yayılış gösterdiği alanlardır. İçine Juniperus communis, J. excelsa, Quercus libani ve Acer platanoides gibi çalılar karışmıştır. İran-Turan endemiklerinden kabul edilen İspir meşesi, Tercan-Aşkale arasında yükselen Meyram Dağı üzerinde de yayılış gösterir (Öztürk vd., 2015). Bağırpaşa Dağı ile Esence Dağları arasında yer alan Karasu Irmağı'nın açmış olduğu Sansa Boğazı'nın her iki yamacı İspir meşesinin, Ouercus brantii, $Q$. infectoria subsp.boissieri, Q.petraea subsp.pinnatiloba, Q.trojana, Q.libani, Q.robur subsp.pedunculiflora ile birlikte orman oluşturduğu yerlerdendir (Kaya, 1999).

Tunceli-Elazığ-Bingöl-Muş-Bitlis arasındaki dağlık kesimler tür bakımından zengin meşe ormanlarına sahiptir. Burada meşe ormanını oluşturan en önemli türler arasında $Q$. petraea subsp. pinnatiloba, Q. robur subsp. pedunculiflora, $Q$. infectoria subsp. boissieri, $Q$. brantii, $Q$. ubani, $Q$. cerris ile birlikte $Q$. macranthera subsp. syspirensis de sayılmıştır (Davis, 1965; Odabaşı, 1976; Yaltırık, 1984; Odabaş ve Boydak, 1984; Behçet ve Arık, 2013).

Erciyes Dağı'nın kuzey ve güney yamaçlarında 1100-2200 metre yükseltileri arasında yayılış gösterdiği tespit edilmiştir. Bu vol- 
kanik kütlenin Ali Dağı güney yamacı, Hisarcık Koruluğu, Yılanlı Dağı kuzeyi, Göğ Dağı ve ayrıca dağın güneyinde Kulpak köyü civarı bitkinin yayılış gösterdiği başlıca alanlardır. Ali Dağı'nın güney yamacında 1300-1800 metreler arasında tüylü meşe (Oercus pubescens subsp.anatolica) ile Hisarcık yakınlarında ise saplı meşe (Ouercus robur subsp.robur) ile birlikte topluluk oluşturur (Ünaldı, 1996).

\section{2. İspir Meşesi'nin (Quercus Macranthera Subsp. Syspirensis) Farklı Bir Yayılış Alanı: Hınzır Dağı}

Bitkinin yetişmesi, ekolojik şartlara bağııdır. Bu nedenle sahanın jeolojik, jeomorfolojik, iklim ve toprak özelliklerinin ortaya konulması gerekir. Bunlar bitkinin gelişip büyümesi, şekillenmesi, topluluklar oluşturması ve yayılması üzerinde bir bütün halinde etkilidir. Quercus syspirensis'in yayılış gösterdiği alan ve çevresinin başlıca özelliklerine kısaca değinilmiştir. Hınzır Dağı'nın (2477 m) kuzeybat yamacında etek kısımlarda yer alan bu meşe türü 1600-1800 metreler arasında Tavşan Tepe'nin yanı başındaki Tatlıöz Deresi'nin yukarı çığırında vadi içerisine sıkışmış durumdadır (Şekil 3).

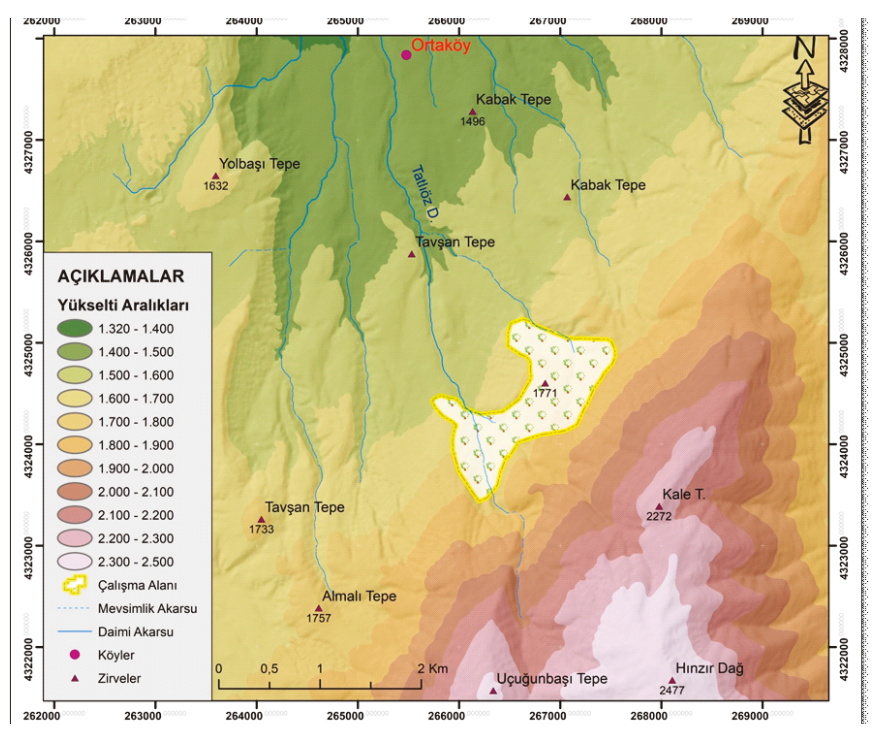

Şekil 3. İspir meşesinin (Quercus macranthera subsp. syspirensis) yayılış alanı ve yakın çevresinin topografya haritası

Figure 3. Topography map of the distribution area and surroundings of ispir oak (Quercus macranthera subsp. Syspirensis)

\subsection{Sahanın İklim Özellikleri}

Sıcaklık, nem, yağış ve rüzgâr gibi iklim elemanlarının ortak etkileri, o yerin bitki örtüsünün şekillenmesinde başlıca rol oynar (Dönmez, 1985; Güngördü, 1999). Sahanın iklim özelliklerinin ortaya konulmasında Gemerek, Şarkışla ve Pınarbaşı (Kayseri) meteoroloji istasyonun verilerinden yararlanılmıştır. Alanda karasal iklim hüküm sürmektedir. Bu iklim tipi kışların soğuk, yazların ise sıcak ve kurak olması ile karakterize olur. Mevsimler arasında sıcaklık farkı fazladır. Meteoroloji istasyonlarından Gemerek ve Pınarbaşı'nın 55 yıllık (1964-2018) ve Şarkışla'nın ise 40 yıllık (1964-2005) verilerine göre yılık ortalama sıcaklık 7,8$9,5^{\circ} \mathrm{C}$ arasında değişmektedir (Tablo 1 ). İstasyonların hepsinde, kış mevsimini oluşturan ayların ortalama sıcaklık değeri $0^{\circ} \mathrm{C}^{\prime}$ nin altındadır. Ocak ayı en düşük sıcaklığa sahiptir $\left(-2,9^{\circ} \mathrm{C}\right.$ ile $-4,4^{\circ} \mathrm{C}$ arasında). Pınarbaşı'nda ocak ayı ortalama sıcaklık $-4,4^{\circ} \mathrm{C}^{\prime}$ ye kadar düşer. Gemerek ve Şarkışla'da sıcaklığın en fazla olduğu aylar temmuz ve ağustostur. Pınarbaşı'nda ise ağustos ayının sıcaklık ortalaması $19^{\circ} \mathrm{C}$ 'dir. Pınarbaşı'nda hiçbir ayın ortalama sıcaklığı $20^{\circ} \mathrm{C}$ 'nin üzerine çıkmaz.

Tablo 1. Araştırma Sahasında Uzun Yıllara Ait Aylık Ortalama Sıcaklıklar $\left({ }^{\circ} \mathrm{C}\right)$ Table 1. Average Monthly Temperatures for Many Years in the Research Area $\left({ }^{\circ} \mathrm{C}\right)$

\begin{tabular}{|c|c|c|c|c|c|c|c|c|c|c|c|c|c|c|}
\hline \multirow{2}{*}{$\begin{array}{l}\text { İstasyon Adı } \\
\text { ve Yükseltisi }\end{array}$} & \multirow{2}{*}{\begin{tabular}{|l} 
R.Süresi \\
(Yul)
\end{tabular}} & \multicolumn{12}{|c|}{ Aylar } & \multirow[t]{2}{*}{ Yilllk } \\
\hline & & 0 & Ş & M & $\mathrm{N}$ & $\mathrm{M}$ & $\mathrm{H}$ & $\mathrm{T}$ & A & E & Ek & $\mathrm{K}$ & A & \\
\hline $\begin{array}{l}\text { Gemerek- } \\
1182 \mathrm{~m}\end{array}$ & 55 & $-3,2$ & $-1,5$ & 4,0 & 9,6 & 13,7 & \begin{tabular}{|l|l}
17,7 \\
\end{tabular} & 21,1 & 21,1 & 16.8 & 11,1 & 4,5 & $-0,5$ & 9,5 \\
\hline $\begin{array}{l}\text { Șarkșıla- } \\
1180 \mathrm{~m}\end{array}$ & 40 & $-2,9$ & $-2,0$ & 3,5 & 9,4 & 13,6 & 17,3 & 20,6 & 20,6 & 17,0 & 11,8 & 5,0 & $-0,1$ & 9,5 \\
\hline $\begin{array}{l}\text { Pınarbașl- } \\
1542 \mathrm{~m}\end{array}$ & 55 & $-4,4$ & $-3,0$ & 2,0 & 7,7 & 11,8 & 15,5 & 18,8 & 19,0 & 14,9 & 9,5 & 3,4 & $-1,7$ & 7,8 \\
\hline
\end{tabular}

Yıllık yağış miktarı ise $407-430 \mathrm{~mm}$ arasında seyreder (Tablo 2). Yıllık toplam yağış miktarı Şarkışla'da 407,7 mm, Gemerek'te 409,9 mm, Pınarbaşı'nda ise 429,9 mm olarak ölçülmüştür (Tablo 2).

Tablo 2. Araştırma Sahasında Uzun Yıllara Ait Aylık Ortalama Yağış Değerleri (mm)

Table 2. Monthly Average Rainfall Values for Many Years in the Research Area (mm)

\begin{tabular}{|c|c|c|c|c|c|c|c|c|c|c|c|c|c|c|}
\hline \multirow{2}{*}{$\begin{array}{l}\text { Istasyon Add } \\
\text { ve Yükseltisi }\end{array}$} & \multirow{2}{*}{$\begin{array}{l}\text { R.Süre } \\
\text { (Yil) }\end{array}$} & \multicolumn{12}{|c|}{ Aylar } & \multirow[t]{2}{*}{ Yillik } \\
\hline & & 0 & S & M & $\mathrm{N}$ & M & $\mathrm{H}$ & $\mathrm{T}$ & $\mathrm{A}$ & Ey & Ek. & $\mathrm{K}$ & A & \\
\hline $\begin{array}{l}\text { Gemerek } \\
(1182 \mathrm{~m})\end{array}$ & 55 & 42,8 & $\begin{array}{l}33,5 \\
\end{array}$ & \begin{tabular}{|l|}
42,7 \\
\end{tabular} & \begin{tabular}{|l|}
51,5 \\
\end{tabular} & \begin{tabular}{|l|}
53,3 \\
\end{tabular} & 35,4 & 8,7 & 9,7 & \begin{tabular}{|l|}
13,7 \\
\end{tabular} & \begin{tabular}{|l|}
32,5 \\
\end{tabular} & 40,5 & 45,6 & 409,9 \\
\hline $\begin{array}{l}\text { Sarksşla- } \\
(1180 \mathrm{~m})\end{array}$ & 40 & 36,1 & 36,6 & \begin{tabular}{|l|}
38,2 \\
\end{tabular} & \begin{tabular}{|l|}
50,3 \\
\end{tabular} & \begin{tabular}{|l|}
61,3 \\
\end{tabular} & 36,5 & 14,0 & 8,2 & \begin{tabular}{|l}
14,4 \\
\end{tabular} & \begin{tabular}{|l}
30,8 \\
\end{tabular} & 38,5 & 42,8 & 407,7 \\
\hline $\begin{array}{l}\text { Pinarbaş } 1 \\
(1542 \mathrm{~m})\end{array}$ & 55 & 36,1 & 35,1 & \begin{tabular}{|l|}
46,6 \\
\end{tabular} & 56,9 & \begin{tabular}{|l|l}
59,9 \\
\end{tabular} & \begin{tabular}{|l|}
39,7 \\
\end{tabular} & 8,7 & 11,7 & 17,2 & \begin{tabular}{|l|}
34,6 \\
\end{tabular} & 39,7 & 43,7 & 429,9 \\
\hline
\end{tabular}

Mevcut meteoroloji istasyonlarının verilerine göre yağışın mevsimlere dağılışı düzensizdir. En yağışlı mevsim ilkbahardır (Gemerek \% 36, Şarkışla \% 36,7, Pınarbaşı \% 38). Bunu kış mevsimi takip eder. En az yağış ise yaz mevsiminde gerçekleşir (Gemerek $\%$ 21,6, Şarkışla \% 20,5, Pınarbaşı \% 21,3). Yağışın yıllara göre dağılışı da çok düzensiz seyreder (Tablo 3).

Tablo 3. Araşttrma Sahasında Uzun Yıllara Ait Ortalama Yağış Değerlerinin Mevsimsel Dağılışı

Table 3. Seasonal Distribution of Average Rainfall Values for Long Years in the Research Area

\begin{tabular}{|c|c|l|l|l|l|l|}
\hline $\begin{array}{l}\text { İstasyon Adı ve } \\
\text { Yükseltisi (m) }\end{array}$ & $\begin{array}{l}\text { R.Süresi } \\
\text { (Yıl) }\end{array}$ & $\begin{array}{l}\text { Kıș } \\
(\mathbf{m m})\end{array}$ & $\begin{array}{l}\text { İkbahar } \\
(\mathbf{m m})\end{array}$ & $\begin{array}{l}\text { Yaz } \\
(\mathbf{m m})\end{array}$ & $\begin{array}{l}\text { Sonbahar } \\
(\mathbf{m m})\end{array}$ & $\begin{array}{l}\text { Toplam } \\
\text { Yağıș(mm) }\end{array}$ \\
\hline $\begin{array}{l}\text { Gemerek } \\
(1182 \mathrm{~m})\end{array}$ & 55 & 121,9 & 147,5 & 53,8 & 86,7 & 409,9 \\
\hline$\%$ & & 29,7 & 36,0 & 13,1 & 21,2 & 100,0 \\
\hline $\begin{array}{l}\text { Şarkışla } \\
(1180 \mathrm{~m})\end{array}$ & 40 & 115,5 & 149,8 & 58,7 & 83,7 & 407,7 \\
\hline$\%$ & & 28,3 & 36,7 & 14,4 & 20,5 & 100,0 \\
\hline $\begin{array}{l}\text { Pınarbaş1 } \\
(1542 \mathrm{~m})\end{array}$ & 55 & 114,9 & 163,4 & 60,1 & 91,5 & 429,9 \\
\hline$\%$ & & 26,7 & 38,0 & 14,0 & 21,3 & 100,0 \\
\hline
\end{tabular}

\subsection{Sahanın Jeolojik ve Jeomorfolojik Özellikleri}

Saha ve çevresinde en yaşlı litolojik birimi Hınzırdağı Kireçtaşları oluşturur (Şekil 4). Hınzır Dağı kütlesinin çok büyük ölçüde yapısına giren bu formasyon, kireçtaşlarından ibarettir. Kireçtaşları belirgin katmanlanma göstermeyen, gri-siyahımsı renkli, çok fazla tektonizmaya uğramış, çatlaklı ve kalsit dolguludur ve 
Triyas yaşı verilmiştir. (Gökten, 1981). Hınzır Dağı üzerinde bu formasyonun yayılış gösterdiği yerlerde tipik karstik şekiller gelişmiştir (Sunkar, 2008).

Hınzırdağı Kireçtaşı üzerine uyumsuz olarak bitümli seyl, çamurtaşı, kireçtaşı, kiltaşı, silttaşı tabakalarından ve volkanoklastiklerden oluşan Ortaköy Formasyonu gelmektedir (Gündoğan vd., 2005). Bu formasyonu oluşturan tabakalar batyya doğru $10-55^{\circ}$ arasında değişen eğime sahiptir. Formasyon, içindeki makro fosillere göre Orta-Üst Eosene aittir (Tekeli vd., 1992). Araştrrmamıza konu olan İspir meşesi (Quercus syspirensis) topluluğu, bu litolojik birim üzerinde yayılış gösterir.

Bu formasyon üzerine Oligosen yaşlı Tuzhisar Formasyonu uyumlu olarak gelir. Tuzhisar Formasyonu, karasal tortullarla temsil edilir. Masif, yer yer tabakalı, beyaz-sarımsı, gri renkli değişik kalınlıkta jipsler ile kırmızı, sarımsı kiltaşı, çamurtaşı, çakıltaşı ve konglomeralardan ibarettir. Jipsler, Korumaz dağlarının kuzeybatı ucundan Hınzır dağları bölgesine ve Kızılırmağa kadar, Korumaz-Hınzır sıra dağlarının kuzeyinde uzanan geniş bir alanda yayılış göstermektedir (İzırak, 1944).

Kuvaterner ise akarsu boylarındaki alüvyonlarla ve Hınzır Dağı yamacında yamaç döküntüleri ile temsil edilir. Eski Ortaköy yerleşmesi ile Küçük Tuzhisar arasındaki Acısu Dere vadi tabanında alüvyonlar yüzeylenir (Şekil 4).

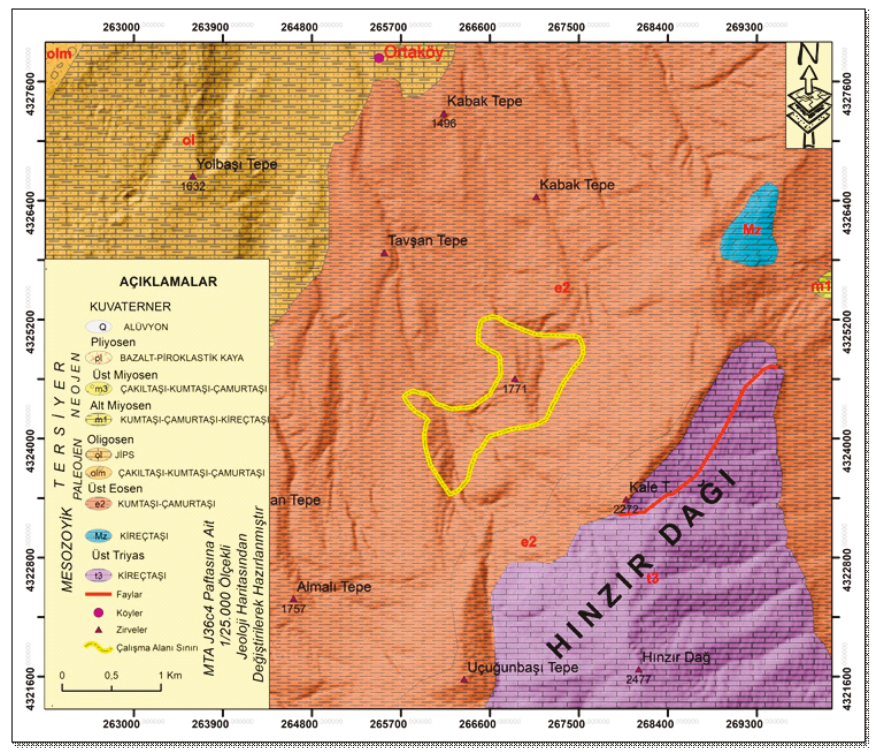

Şekil 4. İspir meşesi (Quercus macranthera subsp. syspirensis)'nin yayılış gösterdiği alan ve yakın çevresinin jeoloji haritası

Figure 4. Geological map of the distribution area of Ispir oak (Quercus macranthera subsp. syspirensis) and surroundings

Araştırma sahası ve çevresinin monoklinal yapıya sahip olduğu arazi gözlemleri sonucunda tespit edilmiştir. Monoklinal yapıyı oluşturan tabakalar batiya doğru eğimlidir. Dış kuvvetler tarafindan tabakalar aşındırılarak alnı doğuya yani Hınzır Dağı'na bakan kuestalar şeklinde belirmiştir (Şekil 5). Batyya doğru eğimli tortul tabakalar üzerinde drenaj ağını kuran, sularını Kızılırmak Nehri'ne ve Tuzla Gölü Kapalı Havzası'na boşaltan konsekant karakterli Acıöz, Acısu, Gümüş Dere, Kestuvan Çayı ve Değirmentaşı Dere gibi akarsular kuzeydoğu-güneybat doğrultusunda sıralanan Girinci, Kululu, Akkışla, Gömürgen ve Ortaköy sübsekant depresyonlarını oluşturmuşlardır. Söz konusu akarsuların, sübsekant depresyonu terk ettiği yani konsekant vadiye giriş yaptıkları yerlerde yerleşmelerin konumlandığı dikkati çekmektedir.

Bu sübsekant depresyonları batıdan jips tabakalarından yapılı kuestalar kuşatır. Eski Ortaköy yerleşmesi kuzeybatısında olduğu gibi kuesta sırtlarını oluşturan jipsler içinde dolinler, mağaralar ve düdenler gelişmiştir (Şekil 5). Önceden kuesta alnının alt kesiminde bulunan Ortaköy yerleşmesi, meydana gelen çökmelerden dolayı depresyonun merkezi kısmına taşınmıştır. İspir meşesinin sübsekant depresyonunda yayılış gösterdiği alanda aşınıp ortadan kalktı̆ından dolaya jips bulunmamaktadır.

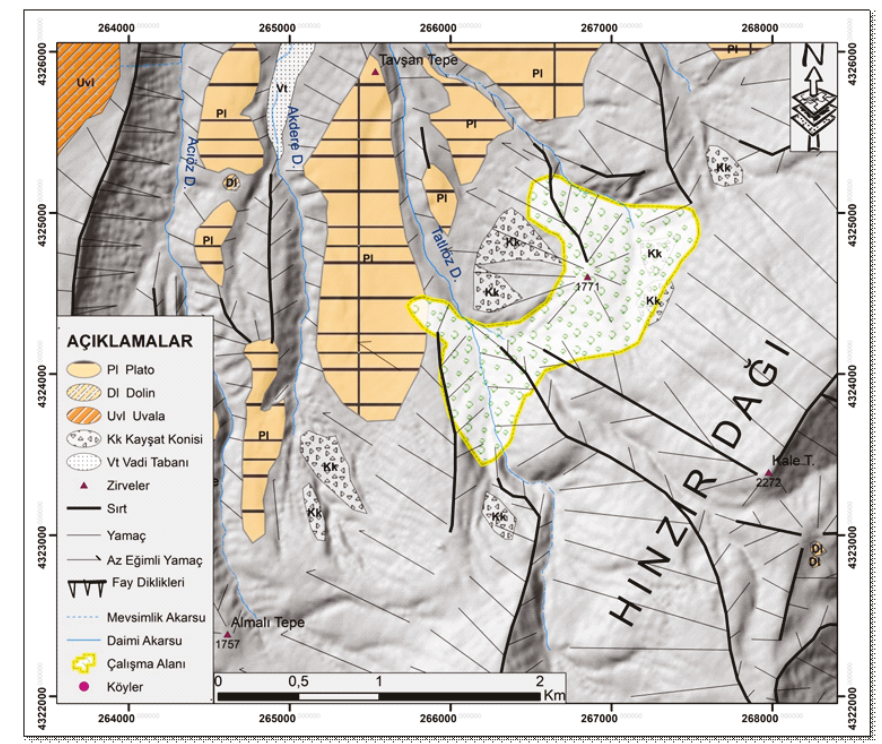

Şekil 5. İspir meşesi (Quercus macranthera subsp. syspirensis) yayılış gösterdiği alan ve çevresinin jeomorfoloji haritası

Figure 5. Geomorphology map of the distribution area of ispir oak (Quercus macranthera subsp. syspirensis) and surroundings

\subsection{Sahanın Toprak Özellikleri}

Ortaköy depresyonu ve çevresinde kahverengi, kırmızı kahverengi ve alüvyal topraklar gelişme imkânı bulmuştur (Şekil 6). İspir meşesinin (Quercus syspirensis) yayılış gösterdiği alanda hâkim toprak grubunu kahverengi topraklar oluşturur. Bu toprak grubu İç Anadolu'nun yaygın ve tipik toprağıdır (Toprak Su Genel Müdürlüğü, 1974). Araştırma sahasında Eosene ait bitümli seyl, çamurtaşı, kireçtaşı, kiltaşı, silttaşı gibi tortul kayaçlar üzerinde gelişmiş olan bu topraklar A, B ve C horizonludur. A horizonu granüler yapılı ve balçık tekstürüne sahip olup nötr ve hafif alkalen reaksiyon özelliği taşır. Bu kat kahverengine sahiptir. B horizonu balçıklı, killi balçıklı bünyeli kaba granüler yapıdadır. Ayrıca horizonun alt kısmında düşen yağışlar sonucunda yıkanarak altta birikerek kireç lekeleri oluşmuştur. Kireç birikimini diğer horizonlarda da görmek mümkündür. İspir meşesinin yayılış gösterdiği yerlerde kahverengi toprak örtüsünün eğim nedeniyle toprağın süpürülmüş olmasından dolayı çok inceldiği ve ana materyalin yüzeye çıktığı dikkati çekmektedir. Sahada bu toprağın yayılış gösterdiği alanlarda drenaj şartları iyi durumdadır. Karaziyaret Tepe (1629 m), Tavşan Tepe (1733 m), Ortaköy, Küçük Tuzhisar arasındaki alan bu toprakla örtülüdür (Şekil 6). Hınzır Dağı yamaçları ise erozyon nedeniyle toprak örtüsünden yoksun kayalık alan halindedir. Nitekim bu alanın ortalama eğim derecesi 20,6 civarındadır (Şekil 7). 


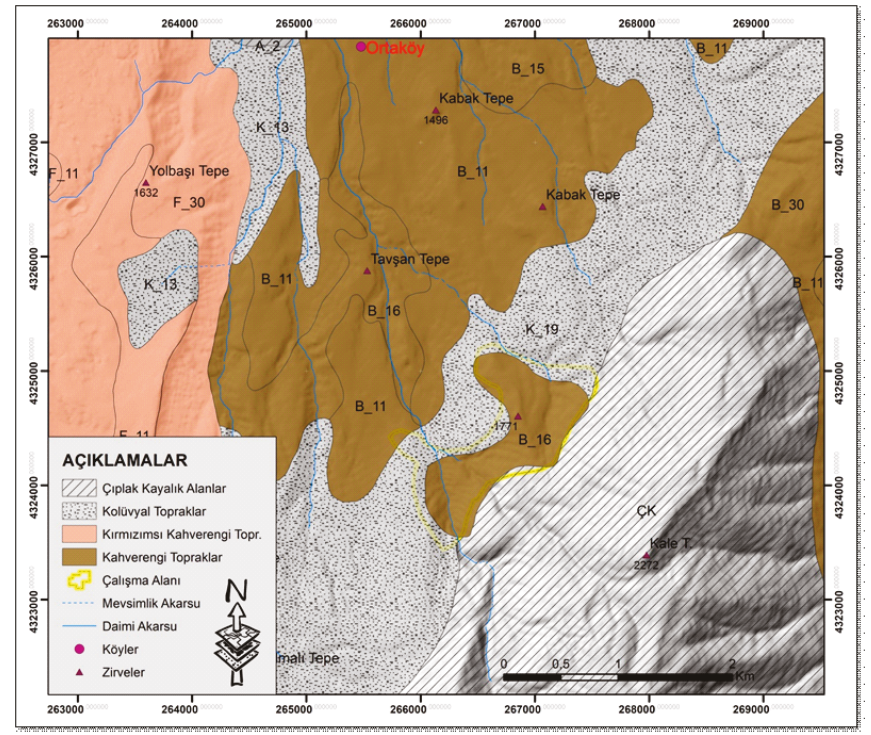

Şekil 6. İspir meşesi (Quercus macranthera subsp. syspirensis) yayılış alanı ve çevresinin toprak haritası

Figure 6. Soil map of the distribution area of ispir oak (Quercus macranthera subsp. syspirensis) and surroundings

Kırmızı kahverengi topraklar Ortaköy batısında, Tuzhisar kuzeyinde yayılış gösterir. İklim şartlarının ve litolojik özelliklerin toprak rengi üzerinde etkisi olduğu bu toprağın üst kısmı koyu kahve-kırmızımsı kahverengi arasında değişmektedir. Özellikle jipsler üzerinde gelişmiş olan bu toprakları Küllü Tepe (1701 m) çevresinde Pur olarak nitelendirilen mevkide, Küçük Tuzhisar kuzeyinde Sivri Tepe (1759 m) ve Armutlukoyak Tepe (1810 m) çevresinde görmek mümkündür.

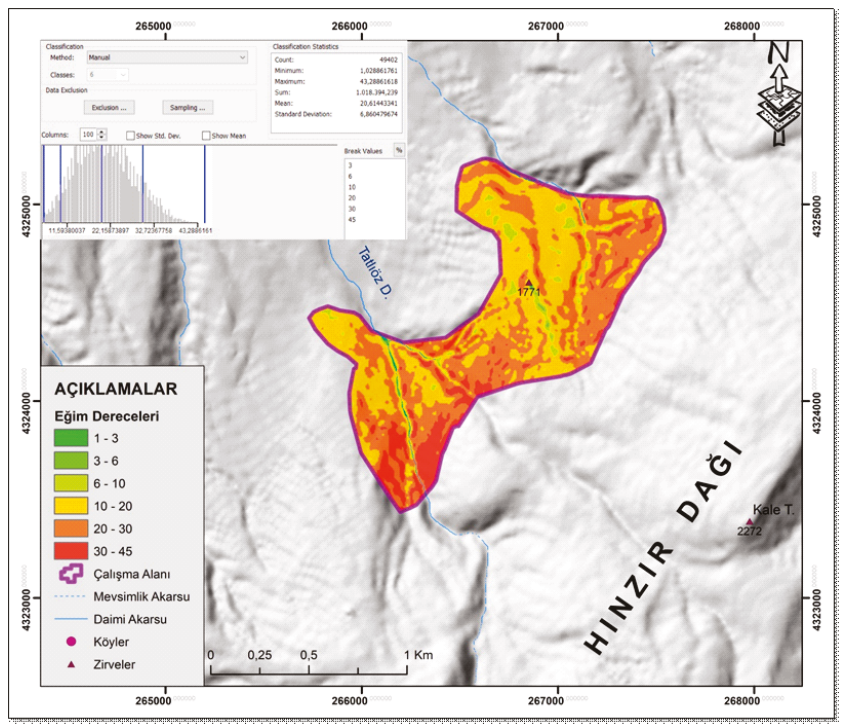

Şekil 7. İspir meşesi (Quercus macranthera subsp. syspirensis) yayılış alanının eğim haritası

Figure 7. Slope map of the distribution area of ispir oak (Quercus macranthera subsp. syspirensis)

Mevsimlik ve daimî akışa sahip akarsuların taşıyıp getirdiği alüvyonları eğimin ve hızın azaldığı yerlerde bırakması ile oluşan azonal grupta yer alan alüvyal topraklar ise sınırlı alana sahiptir. Bu genç topraklara Ortaköy ile Küçük Tuzhisar köyleri arasında Acısu vadisinde rastlanılmaktadır.

\section{Bulgular}

Araştırmaya konu olan İspir meşesi (Quercus syspirensis), Hınzır Dağı (2477 m) kuzeybat yamacında yer alır. Meşe topluluğu, Ortaköy yeni yerleşim alanına $4 \mathrm{~km}$ uzaklıktadır. Büyük Meşe ve Küçük Meşe olarak nitelendirilen başlıca iki topluluk halinde, Acıöz Dere'nin kolu olan Tatlı̈z Deresi yukarı havza kısmında vadi içinde topluluklar oluşturmuştur (Foto 2,3). Burada 16001800 metre yükselti basamakları arasında yayılış gösterir.

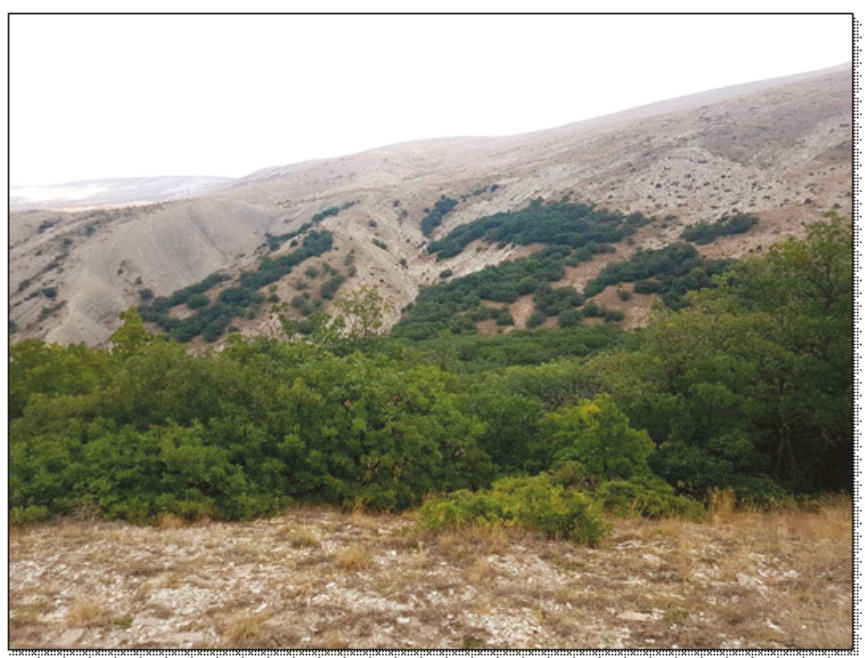

Fotoğraf 2. Tatlıöz Deresi kabul havzası (yukarı çı̆̆ır) kısmında Quercus syspirensis topluluğu (güneyden kuzeye bakış).

Photo 2. Quercus syspirensis group in the Tatlıöz Stream acceptance basin (groundbreaking up) (view from south to north).

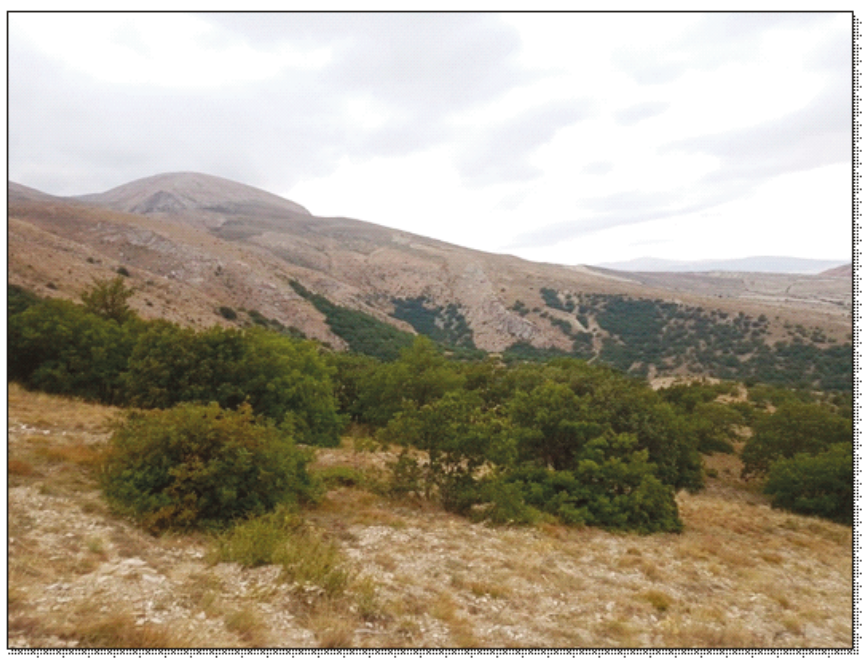

Fotoğraf 3. Tatlıöz Deresi kabul havzası (yukarı çı̆̆ır) kısmında Quercus syspirensis topluluğu.

Photo 3. Quercus syspirensis group in the Tatlıöz stream acceptance basin (groundbreaking up)

Daha çok çalı ve ağaççık formunda olup, maksimum 5 metreye kadar boylanmış ve gövde çapı maksimum 20 cm'ye ulaşan bireyler halindedir. İspir meşesine, J.oxycedrus subsp.oxycedrus, Acer tataricum, A.hyrcanum, Euonymus verrucosus, E.latifolius, beyaz yapraklı üvez (Sorbus umbellata), akçaağaç yapraklı üvez (S.torminalis), boz armut (Pyrus elaeagnifolia), geyik dikeni (Crataegus orientalis) gibi türler karışır (Foto 4). Bunun yanında Rosa canina, R.pulverulenta, R.heckeliana, Viburnum lantana, 
Berberis crataegina gibi çalı türleri meşe ormanı kalıntısı arasında dağınık olarak rastlanılmaktadır (Şekil 8). Meşe topluluğunun çevresi ise antropojen özellik taşıyan step formasyonu ile örtülüdür. Aşırı otlatma nedeniyle İran-Turan Flora Bölgesi'ne ait step elemanları floristik açıdan fazla çeşitliliğe sahip değildir. Geven (Astragalus sp.), sütleğen (Euphorbia sp.), yumak (Festuca valesiaca), çoban yastı̆̆ (Acantholimon sp.) ve kadın tuzluğu (Berberis crataegina) en yaygın türlerdir.

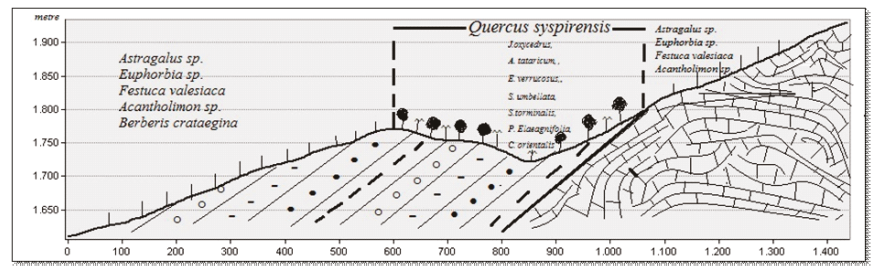

Şekil 8. Hınzır Dağı'nın kuzeybatt kesiminin doğu-bat yönünde bitki kesiti Figure 8. Plant section in E-W direction of northwest part of Hınzır Mountain

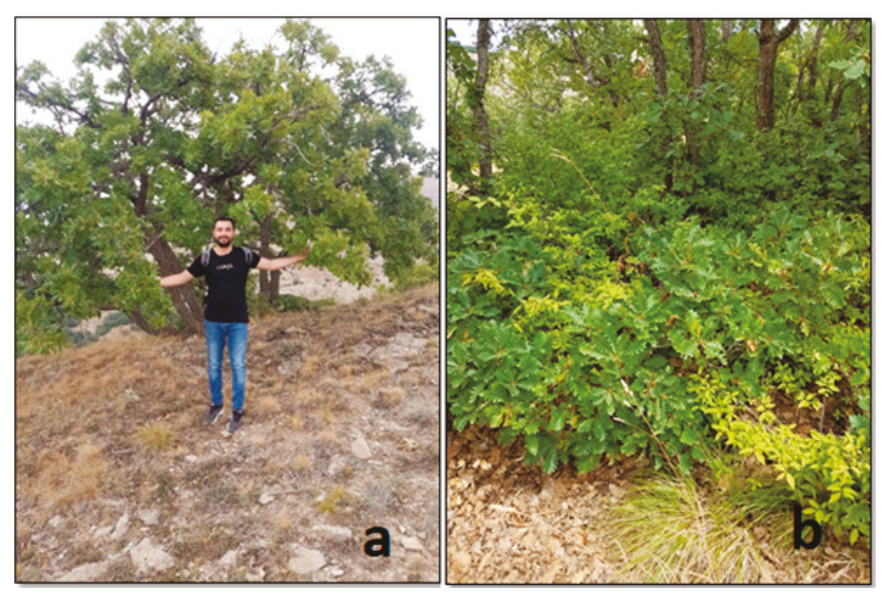

Fotoğraf 4. a) Quercus syspirensis boyları en fazla 5 metreye kadar boylanabilmektedir. b) Quercus syspirensis topluluğu içinde Euonymus verrucosus gibi bitki türlerine de rastlanılmaktadır.

Photo 4. a) The maximum lengths of Quercus syspirensis can be up to 5 meters. b) Plant species such as Euonymus verrucosus are also found in the Quercus syspirensis community.

\section{Sonuç}

Bu çalışmada endemik bir alt tür olan İspir meşesinin (Quercus macranthera subsp. syspirensis) ülkemizdeki doğal popülasyonlarının güncel durumu hakkında daha önce çalışma bulunmayan Hınzır Dağı'ndaki yayııışı ve sahanın genel ekolojik özellikleri ortaya konulmuştur. İspir meşesi, İç Anadolu Bölgesi ile Doğu Anadolu Bölgesi arasındaki Anadolu Çaprazı́na komşu olan Hınzır Dağı'nın kuzeybat kısmında yer alır. Dağın sadece Ortaköy yerleşmesi güneyinde 1600-1800 metreler arasında Acıöz Dere'nin kollarından Tatlıöz Deresi kabul havzası kısmında yayılış göstermektedir. Bu yönü ile biyolojik çeşitlilik açısından ender sahalardan biridir. Quercus macranthera subsp.syspirensis Hınzır Dağı'nda çok dar bir alanda yayılış göstermiş olsa da eskiden orman oluşturduğu ancak tahribat sonucunda bugünkü alana hapsolduğunu ileri sürmek mümkündür. Bitkinin step alanlarda lokal olarak bulunması bu durumun işaretidir. Bu endemik türün Hınzır Dağı'nda günümüze kadar ulaşmasında özellikle sahanın jeomorfolojik özelliklerinden vadi içlerinde korunaklı alanlarda kalması etkili olmuştur.
Bitki, yüzyıllardır süren yakacak temin etmek gibi çeşitli antropojenik etkilerden, hayvan otlatılması gibi çeşitli nedenlerden dolayı büyük ölçüde tahribata uğramış, küçük lekeler halinde ulaşımın nispeten zor olduğu, topografyanın insan müdahalesini kısıtladığı alanda tutunabilmiştir

İspir meşesi, günümüzde çalı ve ağaççık formunda sahada, orman kalıntısı şeklinde, toprak tabakasının zayıflı̆̆ı ve çeşitli beşerî etkenlerden dolayı hayatta kalma mücadelesi vermektedir. Meşe topluluğu, yöre insanı tarafindan büyükbaş ve küçükbaş hayvanlar için yem olarak kullanılmakta ayrıca yakacak olarak kesilerek tahrip edilmektedir. İç Anadolu Bölgesi'nde çok lokal ortamlarda doğal olarak yetişen bu meşe türünün ortadan kalkmaması için, Hınzır Dağı üzerindeki popülasyonun koruma altına alınması, hayvanların meşe topluluğunun bulunduğu alana girmemesi konusunda gerekli tedbirlerin hayata geçirilmesi gerekmektedir. Quercus macranthera subsp.syspirensis, yarı kurak ekosistem alanların ağaçlandırılmasında iyi bir potansiyele sahiptir. Bu nedenle ağaçlandırma çalışmalarında kullanılabilecek meşe türlerindendir.

\section{Teşekkür}

Yazarlar, bu çalışmanın arazi çalışmalarına katılan Uşak Üniversitesi, Coğrafya Bölüm Öğrencisi Çağatay Can IPEK'e teşekkür ederler.

\section{Kaynakça}

Akkemik, Ü. Editör, (2014). Türkiye'nin Doğal-Egzotik Ağaç ve Çalıları 1, Orman Genel Müdürlüğü yayınları, Ankara.

Akkemik, Ü. (2016). Türkiye'nin Doğal Meşe (Quercus L.) Türlerinin Yayılışı ve Botanik Özellikleri Uluslararası Katılımlı Meşe Çalıştayı 18-20 Ekim 2016, İgneada / Kırklareli .83-94.

Anşin, R. ve Özkan, C. (2006). Tohumlu Bitkiler (Spermatophyha) Odunsu Taksonlar, K.T.Ü, Orman Fak. 167,19, Trabzon.

Atalay, ì. (1994). Türkiye Vejetasyon Coğrafyası, Ege Üniversitesi Basımevi, 226-229, izmir.

Atalay, i. (2017). Türkiye'nin Ekolojik Bölgeleri, OGM Yayını, İzmir.

Avcı, M. (1997). Karasu-Tuzla Çayı Arasındaki Sahada Orman Kalıntları, İstanbul Üniversitesi, Coğrafya Dergisi, Sayı 5,180-224.

Behçet, L. \& Arık, M. (2013). An Ethnobotanical Investigation in East Anatolia (Turkey), Turkish Nature and Science Journal, 2, 1-15.

Browicz, K. \& Zielinski, J. (1984). Chorology of Trees and Shrubs in South-West Asia and Adjacent Regions, Volume 1, Warszawa.

Çağlar, Y. (2003). Dendroloji (Ağaçbilim) ve Orman Ekolojisi Okulu Ders Notları, Kırsal Çevre ve Ormancılık Sorunları Araştırma Derneği yay, No: 13, 70-73, Ankara.

Davis, P. H. (1965). Flora of Turkey and the East Aegean Islands, Volume 7, Edinburgh.

Dönmez, Y. (1985). Bitki Coğrafyası, İstanbul Üniversitesi Edebiyat Fakültesi yayınları no 3319, İstanbul.

Gökten, E. (1981). Şarkışla (Sivas) güney-güneydoğusunun stratigrafisi ve jeolojik evrimi, TÜBITAK T.B.A.G.251, yayımlanmamış rapor, Ankara.

Günal, N. (1997). Türkiye'de Başlıca Ağaç Türlerinin Coğrafi Yayılışları, Ekolojik ve Floristik Özellikleri, Çantay Kitapevi, s. 94-96, İstanbul.

Gündoğan, I., Önal, M. \& Depçi, T. (2005). Sedimentology, petrography and diagenesis of Eosen-Oligocene evaporites:the Tuzhisar Formation, SW Sivas basin, Turkey. Journal of Asian Earth Sciences 25, 791-803.

Güngördü, M. (1999). Marmara Bölgesinin Bitki Coğrafyası, İstanbul Üniversitesi yayın no:4176, Edebiyat Fak. Yay. No:3416, İstanbul.

Hedge, I.C \& Yaltrik, F. (1982). Ouercus L.In;Flora of Turkey and the East Agean Islands (Ed:P.H.Davis).Edinburg University Press, Edinburg, 659-683. 
İzbırak, R. (1944). Yukarı Kızılırmak Bölgesinde Jeomorfoloji Araştırmaları, Ankara Üniversitesi, Dil ve Tarih Coğrafya Fakültesi Dergisi, C:III, S:3, 271-288.

Kaya, Y. (1999). Fırat Vadisi'nde Erozyon ve Erozyon Alanında İyi Gelişen Bitkiler, Tr.J.of Agriculture and Forestry 23 (1999) 7-24.

Kayacık, H. (1981). Orman ve park ağaçlarının özel sistematiği II. Cilt, Angiospermae (Kapalı Tohumlular), İstanbul Üniversitesi Orman Fakültesi, İstanbul Üniversitesi yayın no:2766, Orman Fakültesi yayın no:287, Dördüncü baskı, İstanbul.

Odabaşı, T. (1976). Türkiye'de Baltalık ve korulu baltalık ormanlarının koruya dönüştürülmesi olanakları üzerine araştırmalar. Istanbul Üniversitesi Orman Fakültesi yayınları no. 2079/218, İstanbul.

Odabaşı, T.ve Boydak, M. (1984). Güneydoğu Anadolu Projesinde (GAP) Ormancılığın Yeri ve Katkıları, İstanbul Üniversitesi Orman Fakültesi Dergisi, Seri B, C.34, Sayı 3.

OGM, (2015). Türkiye Orman Varlığı-2015, Orman ve Su İşleri Bakanlığı, Orman Genel Müdürlüğü, Orman İdaresi ve Planlama Dairesi Başkanlığı Yayınları, Ankara.

Öztürk, S. (2013). Türkiye Meşeleri Teşhis ve Tanı Kılavuzu, Orman ve Su İşleri Bakanlığı, Orman Genel Müdürlüğü Yayınları, 188 192, Ankara.

Öztürk, M., Tatlı, A., Özçelik, H. \& Behçet, L. (2015). General Characteristics of Flora and Vegetation Formations of Eastern Anatolia Region and Its Environs (Türkiye), SDU Journal of Science (E-Journal), 2015, 10 (1): 23-48.

Özüdoğru, B., Erik, S. \& Akaydın, G. (2010). The Flora of the Karababa Mountain (Sivas-Şarkışla/Turkey), Biological Diversity and Conservation , 3/3 (2010) 176-192.

Sunkar, M. (2008). Zamantı Çayı Yukarı Havzası (Uzunyayla)'nın Jeomorfolojisi, e-Journal of New World Sciences Academy, Volume: 3, Number: 4.

Tekeli, E., Varol, B., Gökten, E., Keskin, Y., Özaksoy, V. ve Işık, V. (1992). Sivas Havzasının Batı Kesiminin Jeolojisi, Turkish Petroleum Corporation Report No.3173.

Toprak Su Genel Müdürlüğü, (1974). Kızılırmak Havzası Toprakları, Toprak Su Müdürlüğü Yayınları:286, Köy İşleri ve Kooperatifler Bakanlığı Yayınları :203, Raporlar Serisi:71, Cihan Matbaası, Ankara.

Ünaldı, Ü. E. (1996). Erciyes Dağı'nın Fiziki Coğrafyası, Lazer Ofset Basımevi, Ankara.

Yaltııı, F. (1984). Türkiye Meşeleri Teşhis Kılavuzu, Tarım ve Köyişleri Bakanlığı Genel Müdürlüğü Yayınları, Ankara.

Yılmaz, H. (1998). Türkiye'nin Endemik Meşe (Qeurcus L.) Taksonlarının Morfolojik Özellikleri, İstanbul Üniversitesi Fen Bilimleri Enstitüsü, yayımlanmamış doktora tezi, İstanbul.

Zohary, M. (1973). Geobotanical Foundations of the Middle East, Vol.I,II, Stutgart. 